\title{
Longitudinal study of age and order of eruption of primary teeth in Indian children
}

\author{
M. GunaShekhar ${ }^{1}$, John Tenny ${ }^{2}$ \\ ${ }^{1}$ Associate Professor, Faculty of Pediatric Dentistry, NTRUHS, AP, India. \\ ${ }^{2}$ Associate Professor, Faculty of Oral Medicine and Radiology, NTRUHS, AP, India.
}

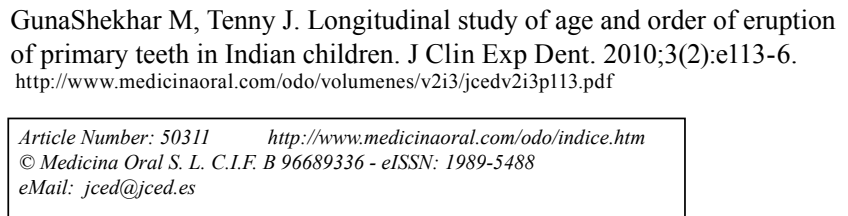

\begin{abstract}
Objective: To determine the chronological eruption parameters of primary teeth in Indian children. Study Design: A longitudinal study consisting of 135 healthy children ( 74 boys and 61 girls) attending three child health centres in the city of Hyderabad, India were randomly selected and followed from the emergence of the first to the last tooth. Ages and order of tooth eruption were studied for both genders. Results: Boys showed tendency towards earlier eruption for all teeth except maxillary second molar and maxillary/mandibular first molars which erupted earlier in girls. Comparison between maxillary and mandibular showed a tendency to earlier mandibular eruption of central incisors, lateral incisors and second molars in both genders. Conclusions: Within the limitations of this study, a baseline data and chronological table for eruption of primary teeth among Indian children has been established. Indian children experienced delayed eruption of primary teeth when compared to their counterparts in other populations.
\end{abstract}

Key words: Eruption, chronology, primary teeth. 


\section{Introduction}

Eruption of deciduous teeth, their exfoliation followed by the eruption of succedaneous permanent dentition is an orderly, sequential, and age-specific event. Most parents are anxious about the timing of eruption which is considered as an important milestone during a child's development (1). Paediatricians' opinion regarding the timing of eruption of primary teeth is often sought by the parents.

Primary teeth have shown wide variations in their eruption pattern and time as well between different population, ethnic and racial groups (2-5). Other suggested factors which affect the eruption time may include gestational period (6), diseases (7), nutritional status and growth (8).

Eruption timing of permanent dentition in different populations have been widely studied, whilst only few studies have been published on primary dentition. Primary teeth eruption has not been investigated in Indian population and information on ages of eruption of primary teeth used in clinical and academic situations in India is based on other populations.

Since individual and environmental factors vary from one geographic location to another, which might affect the timing of tooth eruption and due to the large variability observed in previous studies, it is preferable not to adopt references from other countries as our standard as Indians differ from them racially, culturally, and environmentally. The objective of the present study was to acquire accurate chronological eruption parameters of primary teeth for the Indian population.

\section{Materials and methods}

172 healthy children ( 97 boys and 75 girls) enrolled in the present longitudinal study were followed from the beginning of June 2004 to the end of 2008. The final sample consisted of 135 children ( 74 boys and 61 girls) who were followed from the emergence of the first to the last tooth.

Subjects were randomly selected from three private child care centres of the city of Hyderabad, India and were full-term healthy children, born from uncomplicated pregnancies and deliveries; weighed 2500 grams or more at birth and whose mother and father were Indian nationals. Parents were informed about the study and informed written consent was obtained from parents who were willing to participate in the study. The study was approved by the local ethical and review committee of the Child Health Care centres of Hyderabad.

All the subjects were examined at monthly intervals during the first year of life and then at three-month intervals until full eruption of the primary dentition. Parents were instructed to frequently examine the infants' mouth and record the date of tooth eruption on a specially designed dental chart, kept in the child's health book regularly brought to the paediatricians' office. Eruption time recorded as age ranges were not included.

Dentition status of the subjects, were examined by a pedodontist under good light and by the aid of a blunt probe, during his regular visits to the paediatrician. A tooth was considered erupted when any part of its crown had penetrated the gingiva and is visible in the oral cavity. Data processing and analysis including mean ages (in months) and standard deviation (SD) were calculated by using statistical package SPSS and student t-test was used to assess the statistical significance of the difference in mean age of tooth eruption between males and females at the $5 \%$ significance level.

\section{Results}

The mean eruption times and SD of individual teeth for boys and girls are given in Table 1 and 2. Compa-

\begin{tabular}{|l|l|l|l|l|l|l|l|l|}
\hline \multirow{2}{*}{ Tooth } & \multicolumn{3}{|c|}{ Maxilla } & \multicolumn{4}{c|}{ Mandible } \\
\cline { 2 - 9 } & \multicolumn{2}{|c|}{ Right side } & \multicolumn{2}{c|}{ Left side } & \multicolumn{3}{c|}{ Right side } & \multicolumn{2}{c|}{ Left side } \\
\cline { 2 - 9 } & Mean & SD & Mean & SD & Mean & SD & Mean & SD \\
\hline Central incisor & 11.88 & 0.74 & 12.05 & 0.84 & 10.86 & 0.73 & 10.50 & 0.41 \\
\hline Lateral incisor & 13.35 & 0.88 & 13.36 & 1.03 & 12.55 & 0.92 & 12.66 & 0.79 \\
\hline canine & 21.04 & 1.28 & 21.15 & 1.35 & 22.18 & 1.37 & 21.89 & 1.14 \\
\hline First molar & 17.28 & 1.05 & 17.50 & 1.11 & 19.00 & 0.85 & 19.13 & 0.79 \\
\hline Second molar & 29.29 & 1.02 & 29.48 & 1.39 & 26.82 & 1.80 & 27.16 & 0.78 \\
\hline
\end{tabular}

SD: Standard deviation

Table 1. Mean and Standard deviation age (in months) of eruption of the primary teeth for boys

\begin{tabular}{|l|l|l|l|l|l|l|l|l|}
\hline \multirow{2}{*}{ Tooth } & \multicolumn{4}{|c|}{ Maxilla } & \multicolumn{4}{c|}{ Mandible } \\
\cline { 2 - 9 } & \multicolumn{2}{|c|}{ Right side } & \multicolumn{2}{c|}{ Left side } & \multicolumn{3}{c|}{ Right side } & \multicolumn{2}{c|}{ Left side } \\
\cline { 2 - 9 } & \multicolumn{1}{|c|}{ Mean } & SD & Mean & SD & Mean & SD & Mean & SD \\
\hline Central incisor & 12.00 & 0.74 & 12.16 & 0.85 & 10.97 & 0.72 & 10.56 & 0.42 \\
\hline Lateral incisor & 13.56 & 0.79 & 13.57 & 0.97 & 12.55 & 0.98 & 12.69 & 0.84 \\
\hline canine & 21.17 & 1.36 & 21.32 & 1.40 & 22.35 & 1.41 & 21.99 & 1.21 \\
\hline First molar & 17.09 & 1.06 & 17.16 & 0.92 & 18.94 & 0.93 & 18.91 & 0.74 \\
\hline Second molar & 27.81 & 0.78 & 28.14 & 1.25 & 27.53 & 0.98 & 27.19 & 0.85 \\
\hline
\end{tabular}

SD: Standard deviation

Table 2. Mean and Standard deviation age (in months) of eruption of the primary teeth for girls 


\begin{tabular}{|c|c|c|}
\hline Tooth & & $p$ value \\
\hline 51,61 & -0.11 & 0.42 \\
\hline 52,62 & -0.20 & 0.21 \\
\hline 53,63 & -0.16 & 0.49 \\
\hline 54,64 & +0.26 & 0.14 \\
\hline 55,65 & +1.41 & $0.00^{*}$ \\
\hline 81,71 & -0.08 & 0.41 \\
\hline 82,72 & -0.02 & 0.89 \\
\hline 83,73 & -0.14 & 0.52 \\
\hline 84,74 & +0.17 & 0.23 \\
\hline 85,75 & -0.37 & 0.06 \\
\hline \multicolumn{2}{|c|}{ *Statistically significant difference $(\mathrm{p}<0.05)$} \\
\hline
\end{tabular}

Table 3. Comparison of mean eruption times (in months) between boys and girls (Positive sign indicates earlier eruption in girls)

rison between sexes (Table 3) showed a clear tendency towards earlier eruption in boys for all teeth except maxillary second molar and maxillary and mandibular first molars which erupted earlier in girls. However, statistically significant differences were found only for maxillary second molar in girls $(\mathrm{p}<0.05)$.

When the maxillary and mandibular arches were compared, there was a tendency for central incisors, lateral incisors, and second molars to be chronologically advanced in the mandible when compared to their maxillary counterparts, while canines and first molars emerged earlier in the maxilla, in both boys and girls. Moreover, statistically significant differences were seen for all the teeth in both genders $(\mathrm{p}<0.05)$.

The sequence of eruption of primary teeth was: mandibular central incisors $(10.72 \pm 0.56)$, maxillary central incisors (12.03 \pm 0.79 ), mandibular lateral incisors (12.61 \pm 0.88$)$, maxillary lateral incisors $(13.46 \pm 0.92)$, and maxillary first molars (17.26 \pm 1.03$)$, mandibular first molars (19.02 \pm 0.83$)$, maxillary canines $(21.18 \pm 1.35)$, mandibular canines $(22.10 \pm 1.28)$, mandibular second molars $(27.18 \pm 1.11)$ and finally maxillary second molars $(28.68 \pm 1.12)$.

The results of this study were compared to those of other similar studies involving varying racial and ethnic groups (Table 4). Eruption of the incisors showed slight delay in Indian children when compared to that of children of other nationalities.

\section{Discussion}

Standards for the eruption of primary teeth currently used in most health institutions or clinical and academic situations in India are based on western populations (9). The eruption sequence and growth of the jaws are key elements in the development of functional and aesthetic occlusions. Furthermore, dental formulas are used to estimate biological age and to track children's growth (10).

Longitudinal studies provide information on the ages of eruption of individual teeth, along with their variations

\begin{tabular}{|l|l|l|l|l|l|}
\hline Tooth & $\begin{array}{l}\text { Canada } \\
(1984)\end{array}$ & Spain & $\begin{array}{l}\text { In d i a } \\
(2009) \\
\text { ( P r e - } \\
\text { s e n t } \\
\text { study) }\end{array}$ & Japan & $\begin{array}{l}\text { Austra- } \\
\text { lia } \\
(1984)\end{array}$ \\
\hline Maxilla & \multicolumn{5}{|l|}{} \\
\hline Central & 9.03 & 9.42 & 12.03 & 10.89 & 8.90 \\
\hline Laterals & 10.19 & 10.66 & 13.46 & 12.70 & 10.30 \\
\hline Canines & 18.04 & 18.70 & 21.18 & 18.11 & 18.00 \\
\hline First molars & 15.13 & 15.28 & 17.26 & 17.30 & 15.10 \\
\hline $\begin{array}{l}\text { Second } \\
\text { molars }\end{array}$ & 27.48 & 26.77 & 28.68 & 28.63 & 27.60 \\
\hline Mandible & 7.18 & 7.20 & 10.72 & 9.38 & 7.00 \\
\hline Central & 12.13 & 12.26 & 12.61 & 13.87 & 11.90 \\
\hline Laterals & 18.34 & 19.03 & 22.10 & 19.74 & 18.40 \\
\hline Canines & 15.01 & 15.70 & 19.02 & 17.91 & 15.10 \\
\hline First molars & 26.40 & 25.47 & 27.18 & 27.19 & 26.50 \\
\hline $\begin{array}{l}\text { Second } \\
\text { molars }\end{array}$ &
\end{tabular}

Table 4. Mean eruption times of homologous pair (in months) in longitudinal studies $(4,5,11,12)$

and most frequent order of tooth eruption. Moreover they do not need a large sample size as in cross sectional studies. However, they have disadvantages of taking longer time, require frequent examinations and have a risk of loss of study material (5).

Comparison of the mean eruption times in the present study with other longitudinal studies $(4,5,11,12)$ suggested slightly delayed emergence times of majority of primary teeth in Indian children. These studies have utilized the same design and method for estimation of eruption time. Most of the teeth showed a one to four month variation around the mean eruption time. This may be attributed to disparate geographic, climatic and environmental conditions prevailing in India, which made it difficult to evaluate the role of these factors in the present study and therefore further research is needed. Most studies ascribe the differences to factors like nutrition $(8,13)$ and environmental factors like fluoride content in drinking water (13).. Agarwal et al. (14) had reported delayed deciduous dental eruption in malnourished Indian children.

In the present study, each subject was examined at onemonth intervals during the first year of life followed by three-month intervals until all primary teeth had erupted. Other authors have proposed monthly observations during the study period (12). Majority of the authors $(4,5,11,15)$ have suggested the involvement of instructed parents along with regular examinations of investigators in the examination and registration of data.

In this study, maxillary and mandibular teeth erupted earlier in boys than in girls with the exception of the first molars $(p>0.05)$ and maxillary second molars $(p<0.05)$. Similar results of earlier eruption of first molars in girls than in boys have been reported (11). Reports of gender differences in the timing of eruption of primary teeth are 
unclear in the literature (11). Oziegbe et al. (16) suggested genetic and molecular studies to confirm the possible association of earlier emergence times of primary teeth to accelerated growth in boys during the first trimester. Contradicting the general agreement that lateral incisors erupt first in the maxilla, our study reported statistically significant $(p<0.05)$ earlier eruption of lateral incisors in the mandible. Further, our findings of earlier eruption of second molars in the mandible and the tendency of canines and first molars to be chronologically advanced in the maxilla is in agreement with many authors $(3,4,12)$. Indian children experienced delayed eruption of primary teeth when compared to their counterparts in other populations. The findings of this study establish a new base line data and chronological table for eruption of primary teeth in Indian children and can be used as future reference in clinical and academic research in India. This data will have a significant role for optimal use in the implementation of caries preventive programs like fluoride applications and age estimation in forensic sciences.

\section{References}

1. Pahkala R, Pahkala A, Laine T. Eruption pattern of permanent teeth in a rural community in northeastern Finland. Acta Odontol Scand. 1991;49: 341-9.

2. Lavelle CL. A note on the variation in the timing of deciduous tooth eruption. J Dent. 1975; 3: 267-70.

3. Magnusson TE. Emergence of primary teeth and onset of dental stages in Icelandic children. Community Dent Oral Epidemiol. 1982; 10: $91-7$.

4. Hitchcock NE, Gilmour AI, Gracey M, Kailis DG. Australian longitudinal study of time and order of eruption of primary teeth. Community Dent Oral Epidemiol. 1984;12:260-3.

5. Ramirez O, Planells P, Barberia E. Age and order of eruption of primary teeth in Spanish children. Community Dent Oral Epidemiol. 1994;22:56-9.

6. Seow WK. Effects of preterm birth on oral growth and development. Aust Dent J. 1997;42:85-91

7. Galili G, Rosenzweig KA, Klein H. Eruption of primary teeth and general pathologic conditions. ASDC J Dent Child. 1969;36:51-4.

8. Infante PF, Owen GM. Relation of chronology of deciduous tooth emergence to height, weight and head circumference in children. Arch Oral Biol. 1973;18:1411-7.

9. Lunt RC, Law DB. A review of the chronology of eruption of deciduous teeth. J Am Dent Assoc. 1974;89:872-9.

10. Hernandez M, Espasa E, Boj JR. Eruption chronology of the permanent dentition in Spanish children. J Clin Pediatr Dent. 2008;32:34750 .

11. Tanguay R, Demirjian A, Thibault HW. Sexual dimorphism in the emergence of the deciduous teeth. J Dent Res. 1984;63:65-8.

12. Sato S, Ogiwara Y. Biostatistic study of the eruption order of primary teeth. Bull Tokyo Dent Coll. 1970;12:45-76.

13. Kodali VR. The interface of nutrition and dentition. Indian J Pediatr. 1998;65:529-39.

14. Agarwal KN, Narula S, Faridi MM, Kalra N. Deciduous dentition and enamel defects. Indian Pediatr. 2003;40:124-9.

15. Richardson AS, Castaldi CR. Dental development during the first two years of life. J Can Dent Assoc (Tor). 1967;33:418-29.

16. Oziegbe EO, Adekoya-Sofowora C, Esan TA, Owotade FJ. Eruption chronology of primary teeth in Nigerian children. J Clin Pediatr Dent. 2008;32:341-5.

\section{Acknowledgement}

We express our sincere and special thanks to Dr. P.V.N.Raju, Pediatrician, and Dr. P.Rajeshwari, Dental Surgeon, Hyderabad, India, for their unconditional support. 